\title{
Reappraisal of lignocaine therapy in management of myocardial infarction
}

\author{
B L Pentecost, J V De Giovanni, P LAMB, P J CAdigan, K L EVEMy, \\ E J FLINT \\ From the General Hospital, Birmingham
}

SUMMARY The use of lignocaine in the prevention of ventricular fibrillation among patients admitted to a coronary care unit has been reviewed over the 12-year period 1967 to 1978 inclusive. The practice of suppressing warning ventricular ectopic activity has gradually been abandoned with the result that whereas in 1967 to 196833 per cent of all patients received lignocaine therapy, in 1972 to 1973 the number had fallen to 15 per cent, and in 1977 to 1978 to 4 per cent. The incidence of ventricular fibrillation was not significantly changed at $9 \cdot 1,7 \cdot 7$, and $7 \cdot 8$ per cent, respectively. Approximately 80 per cent of all patients suffering ventricular fibrillation within the coronary care unit were initially resuscitated and approximately 50 per cent survived hospital admission. Death was rarely a result of recurrent ventricular fibrillation and for the most part took the form of pump failure or late unexpected death. Experience suggests that the use of lignocaine to suppress ventricular ectopic activity observed in the first few hours of admission to hospital with acute myocardial infarction has no therapeutic value.

The ability to correct ventricular fibrillation is central to the management of patients with acute myocardial infarction. Successful resuscitation, however, depends on constant vigilance and the immediate availability of skilled operators, a combination of circumstances which is not always achieved. For this reason the prevention of ventricular fibrillation has always been an attractive concept. One approach to the problem has involved the identification of ventricular ectopic activity, considered to provide a warning of impending ventricular fibrillation, and its suppression with antiarrhythmic drug therapy. ${ }^{1-4}$ Though the concept of warning arrhythmias has fallen from favour in recent years, ${ }^{5-7}$ many patients continue to be given antiarrhythmic drugs, particularly lignocaine, in an attempt to suppress certain forms of ventricular premature beats.

Our own use of lignocaine in this manner has diminished considerably over the years. We have recently analysed our experience over a 12-year period in order to determine the influence of this changing therapeutic practice on both the incidence and outcome of ventricular fibrillation.

\section{Patients and treatment}

Three periods, each of two years, have been chosen to illustrate the changing pattern of lignocaine therapy and its consequences between 1967 and 1978 inclusive. During the three periods 1967-68, $1972-73$, and $1977-78$ a total of 1483 patients with acute myocardial infarction was admitted to the coronary care unit (CCU) of the General Hospital, Birmingham. The criteria for the diagnosis of myocardial infarction were a suggestive clinical story together with the progressive development of pathological $\mathrm{Q}$ waves in the electrocardiogram or, when electrocardiographic changes were restricted to progressive $T$ wave inversion, a significant and transient rise in aspartate transaminase.

Details concerning the number of patients studied, their sex, ages, and the median delay from the estimated time of onset of infarction to arrival at the hospital are shown in the Table. There was no

Table Details of patients studied

\begin{tabular}{llll}
\hline & $1967-68$ & $1972-73$ & $1977-78$ \\
\hline Patients & 417 & 517 & 549 \\
Men & $84^{\circ}{ }_{\circ}$ & $83 \%$ & $87 \%$ \\
Age-men & $57 \pm 10$ & $57 \pm 10$ & $58 \pm 10$ \\
$\quad$-women & $64 \pm 10$ & $63 \pm 9$ & $65 \pm 9$ \\
Median delay (h) & 5 & 4.5 & 3.75 \\
\hline
\end{tabular}


significant difference in either sex or age distribution from one period to another. There was, however, a progressive reduction in median delay before hospital admission.

There were substantial changes in both the indications for lignocaine administration in the primary prevention of ventricular fibrillation and the dosage used throughout the 12-year period. In 1967-68 the premonitory arrhythmias of Lown et al. ${ }^{1}$ were closely observed and lignocaine was given in response to the detection of frequent ventricular premature beats (more than five a minute), multiform beats, salvos of two or more ventricular premature beats, and for ventricular premature beats interrupting the $T$ wave of the preceding QRS complex. The inital dose of lignocaine used was $60 \mathrm{mg}$ intravenously, and this dose was repeated until suppression of ventricular premature activity was achieved. The process was repeated if ventricular ectopics returned or, alternatively, a continuous infusion of lignocaine (1 mg a minute) was used. This first period also included the beginning of a trial of routine lignocaine therapy employing a loading dose of $60 \mathrm{mg}$ lignocaine followed by an infusion of either 0.5 or $1 \mathrm{mg}$ a minute for 48 hours, ${ }^{8}$ but only 20 patients were involved in this study during the period under review. In 1972-73 we were no longer treating patients with frequent ventricular premature beats alone but were still suppressing the remaining premonitory arrhythmias: either multiple doses of lignocaine (60 mg intravenously) were used or a single dose of lignocaine (100 mg intravenously) followed by a continuous infusion of between 1 and $2 \mathrm{mg}$ per minute of lignocaine in those cases where ventricular ectopic activity persisted or recurred.9 In 1977-78 only ventricular tachycardia was regarded as an indication for the use of lignocaine in primary prevention. Standard lignocaine dosage was $100 \mathrm{mg}$ intravenously followed by an infusion of

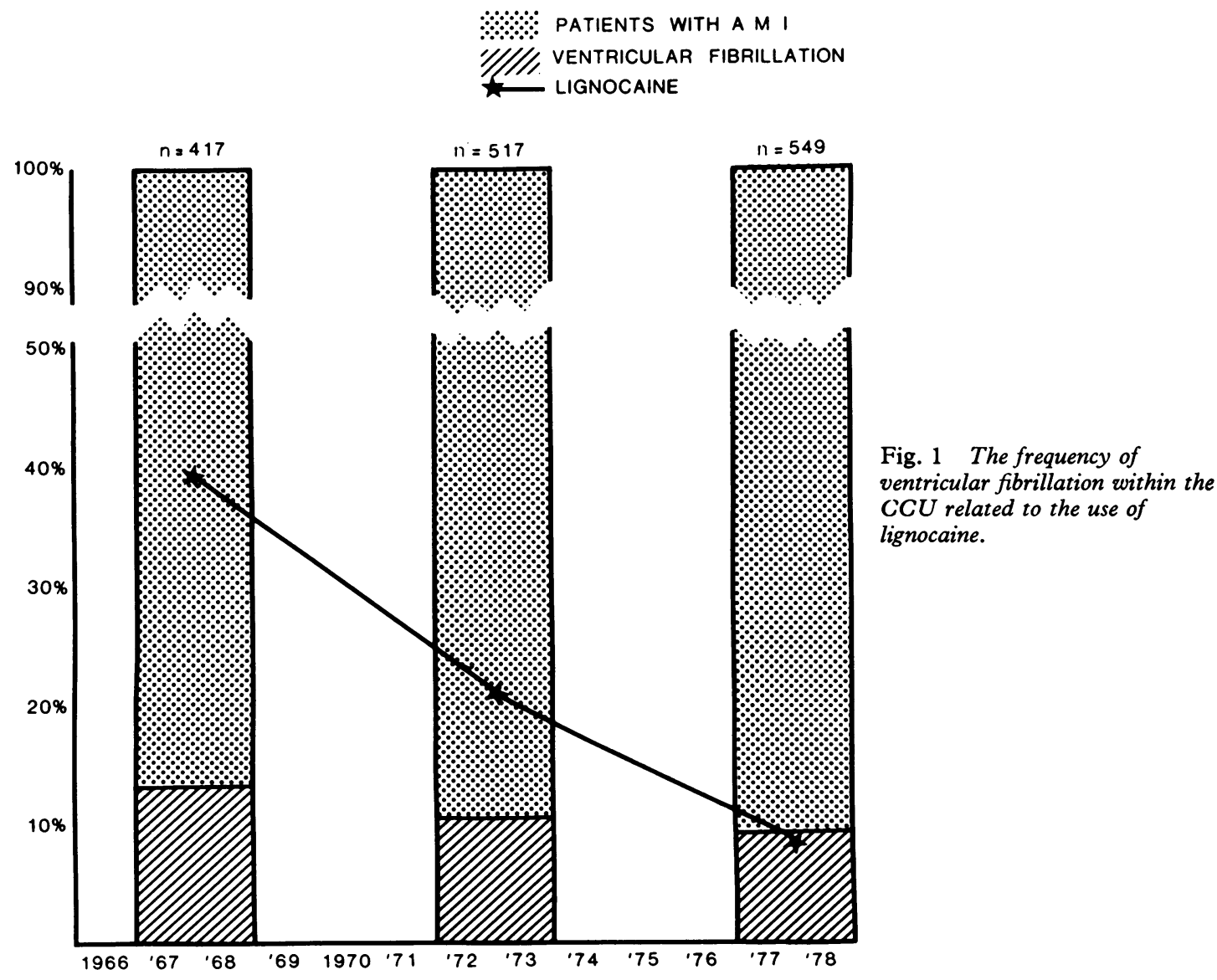

Fig. 1 The frequency of ventricular fibrillation within the $C C U$ related to the use of lignocaine. 
from 1 to $3 \mathrm{mg}$ per minute in those patients in whom ventricular tachycardia recurred. Lignocaine alone was used in these attempts at primary prevention of ventricular fibrillation. Heart failure was not regarded as a contraindication to the use of single injections of lignocaine though great care was taken with such patients in the use of a continuous infusion. Within the context of secondary prevention of ventricular fibrillation, that is the attempted prevention of recurrences of the arrhythmia, lignocaine was the drug of first choice though its failure to control the situation often led to the use of other antiarrhythmic agents.

The statistical significance of changes in either lignocaine therapy or the frequency of ventricular fibrillation from one period to another was assessed by the calculation of $\chi^{2}$.

\section{Results}

The in-patient mortality among patients with acute myocardial infarction treated within the coronary care unit fell insignificantly from 21.6 per cent in 1967-68 to $18 \cdot 2$ per cent in both $1972-73$ and 1977-78.

Lignocaine was administered for either primary or secondary prevention of ventricular fibrillation
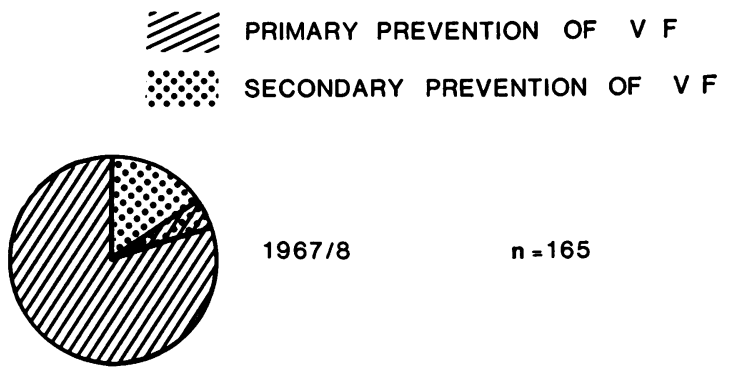

$1967 / 8 \quad n=165$

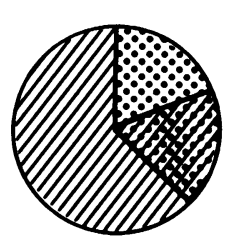

$1972 / 3 \quad n=110$



$1977 / 8$

$n=60$

Fig. 2 Indications for the use of lignocaine within the CCU. to 40 per cent of all patients in 1967-68, to 21 per cent in 1972-73, and to only 10 per cent in 1977-78, but the incidence of ventricular fibrillation among patients during their stay in the unit remained stable at $13.2,10 \cdot 3$, and 9.8 per cent, respectively (Fig. 1). These data underestimate the decline in the use of lignocaine in attempted primary prevention of ventricular fibrillation as a result of the changing policy towards the suppression of ventricular premature beats. In 1967-68 the principal indication for lignocaine therapy was attempted primary prevention whereas by 1977-78 lignocaine was usually used in an attempt to prevent recurrence of ventricular fibrillation (Fig. 2). The data are therefore more appropriately presented to show the decline in the use of lignocaine in primary prevention of ventricular fibrillation against the incidence of ventricular fibrillation occurring for the first time among patients while actually within the coronary care unit, thereby excluding any patients who experienced the first episode of ventricular fibrillation elsewhere in the hospital (Fig. 3). The use of lignocaine in this way fell significantly from 33 per cent of all patients in $1967-68$, to 15 per cent in 1972-73, and to only 4 per cent in 1977-78 $(p<0.001)$. The incidence of ventricular fibrillation was not significantly altered during the three periods at $9 \cdot 1,7 \cdot 7$, and $7 \cdot 8$ per cent.

The outcome among patients suffering ventricular fibrillation while within the CCU is shown in Fig. 4. Successful resuscitation was defined as restoration of spontaneous heart rhythm by direct current countershock. Initial resuscitation was successful in 79 per cent of patients in the first period under study and in 81 and 87 per cent respectively in the subsequent two periods. Survival of patients to the point of discharge from hospital rose from 39 per cent in 1967-68, to 55 per cent in 1972-73, and 50 per cent in 1977-78, but these changes did not achieve statistical significance.

\section{Discussion}

Observations on the significance of ventricular premature beats as predictors of ventricular fibrillation ${ }^{1}$ led to considerable interest both in techniques of ectopic beat detection and in a search for suitable antiarrhythmic drugs. Early studies showed the efficacy of lignocaine in suppressing ventricular ectopic activity ${ }^{2-410}$ and, therefore, by implication, in the prevention of ventricular tachycardia and fibrillation. It became standard clinical practice to attempt suppression of "warning arrhythmias" by the use of lignocaine or other antiarrhythmic drugs. One early study, however, suggested that lignocaine was rather more effective 
at suppressing late unifocal ventricular ectopic beats than the theoretically more dangerous early ( $R$ on $T$ ) or multifocal extrasystoles; ectopic activity was also noted to disappear spontaneously on many occasions. ${ }^{11}$ The same trial found the incidence of ventricular fibrillation to be uninfluenced either by the use of lignocaine or the outcome of attempted suppression of ventricular extrasystoles.

Further doubt has subsequently been cast upon the validity of the "warning arrhythmia" concept. Several studies now confirm that ventricular fibrillation frequently occurs in the absence of warning arrhythmias ${ }^{5-7}$ and that conversely the same degree of ventricular ectopic activity is frequently seen in patients who do not subsequently develop ventricular fibrillation. ${ }^{7}$

Experience in this unit over the past 12 years suggests that detection and suppression of ventricular ectopic activity is of little or no therapeutic value in terms of preventing ventricular fibrillation. There may, however, be a case for the suppression of ventricular activity on haemodynamic grounds as with any tachycardia.

It appears, therefore, that any attempt to prevent ventricular fibrillation must involve administration of the antiarrhythmic drug to all patients at risk. ${ }^{12}{ }^{13}$ Only Lie and his colleagues have provided convincing evidence of effective prophylaxis of ventricular fibrillation by such means. ${ }^{14}$ Dosage is obviously critical for it has been shown that apparent resistance to lignocaine is often dose dependent. ${ }^{15}$ In our own early studies neither a loading dose of lignocaine $60 \mathrm{mg}$ intravenously followed by an infusion of 0.5 or $1 \mathrm{mg}$ per minute for 48 hours $^{8}$ or an intramuscular dose of $200 \mathrm{mg}$ lignocaine followed by an infusion of $2 \mathrm{mg}$ per minute for 48 hours $^{16}$ produced a reduction in the incidence of ventricular fibrillation. Lie et al. ${ }^{14}$ used a higher dose, $100 \mathrm{mg}$ lignocaine intravenously
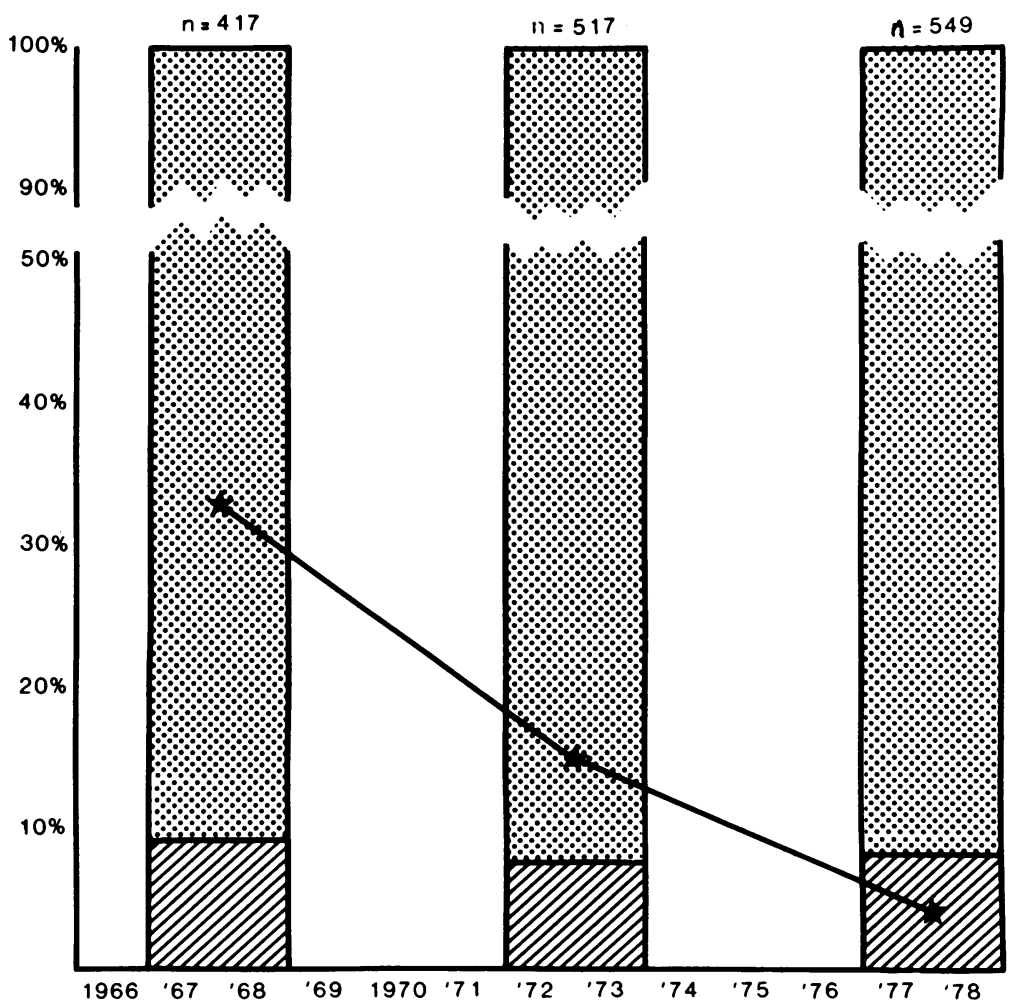

Fig. 3 The frequency of ventricular fibrillation first occurring within the coronary care unit related to the use of lignocaine for primary prevention. 
followed by an infusion of $3 \mathrm{mg}$ per minute. At this dose of lignocaine no ventricular fibrillation was encountered in the active treated group whereas nine of 105 control patients experienced this arrhythmia. It must, however, be emphasised that the patients were highly selected to eliminate those over the age of 70 years and also patients in heart failure, atrioventricular block, or cardiogenic shock. In spite of these exclusions 15 per cent of patients experienced troublesome neurological side effects. The potential toxicity of lignocaine used prophylactically in high dosage should also be considered in the light of the known effects of acute myocardial infarction on lignocaine pharmacokinetics. Myocardial infarction significantly influences the metabolism of lignocaine which occurs within the liver and is critically dependent upon hepatic blood flow. After infarction, even in the absence of clinically apparent heart failure, a constant infusion of lignocaine results in a steady increase in blood level rather than the typical plateau response to infusion in normal subjects. ${ }^{17}$ The presence of heart failure leads to toxic blood levels when quite modest doses of lignocaine are infused and the fall in blood levels on cessation of the infusion is greatly prolonged. Many patients admitted to hospital with acute myocardial infarction would not be suitable for high dose lignocaine infusion and would possibly suffer rather than benefit from such treatment.

It could be argued that the low blood levels of lignocaine resulting from the low dose regimen used particularly in the early years under review might have enhanced the possibility of re-entrant arrhythmias. ${ }^{18}{ }^{19}$ Though this is a legitimate subject for speculation, it is important to emphasise that the dose of lignocaine, $60 \mathrm{mg}$ intravenously, was repeated until suppression of ectopic activity was achieved and that it has been the suppression of ectopic activity which has previously been regarded as being of therapeutic significance.

In-patient mortality among patients experiencing ventricular fibrillation throughout our experience was 50 per cent. The incidence of ventricular fibrillation and its outcome is similar to that recorded in another large series ${ }^{20}$ and has been used as an argument for routine lignocaine therapy for all patients with acute myocardial infarction. It is relevant to the debate, however, that approximately 80 per cent of patients were initially resuscitated and that late death was rarely the result of recurrent ventricular fibrillation. The common cause of death was mechanical or pump failure of the heart and less commonly late sudden death. Neither event is likely to be influenced by the routine use of

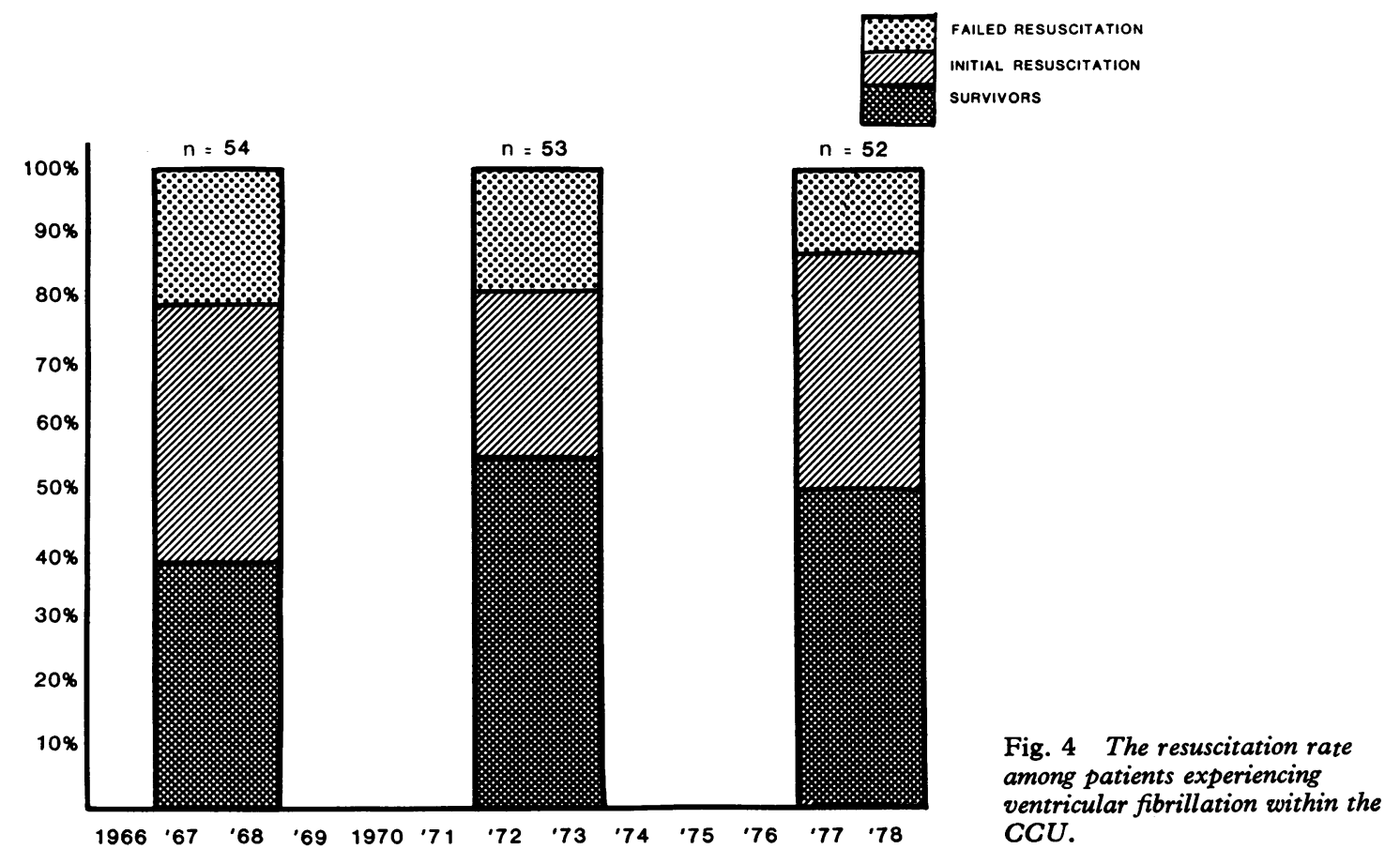

Fig. 4 The resuscitation rate among patients experiencing ventricular fibrillation within the CCU. 
intravenous lignocaine during the first 48 hours of admission to hospital. It could indeed be argued that the main determinant of death or survival is the degree of myocardial damage sustained and that antiarrhythmic prophylaxis of the type under discussion, given that there is a high rate of initial success of resuscitation, is of limited importance in improving hospital survival among patients with acute myocardial infarction.

\section{References}

1 Lown B, Fakhro AM, Hood WB Jr, Thorn GW. The coronary care unit-new perspectives and directions. FAMA 1967; 199: 188-98.

2 Lown B, Vassaux C. Lidocaine in acute myocardial infarction (letter). Am Heart $\mathcal{F}$ 1968; 76: 586-7.

3 Jewitt DE, Kishon Y, Thomas M. Lignocaine in the management of arrhythmias after acute myocardial infarction. Lancet 1968; i: 266-70.

4 Gianelly $R$, von der Groeben JO, Spivack AP, Harrison DC. Effect of lidocaine on ventricular arrhythmias in patients with coronary heart disease. $N$ Engl f Med 1967; 277: 1215-9.

5 Dhurandhar RW, MacMillan RL, Brown KWG. Primary ventricular fibrillation complicating acute myocardial infarction. Am $\mathcal{f}$ Cardiol 1971; 27 : 34751.

6 Bennett MA, Pentecost BL. Warning of cardiac arrest due to ventricular fibrillation and tachycardia. Lancet 1972; i: 1351-2.

$7 \mathrm{Lie}$ KI, Wellens HJJ, Downar E, Durrer D. Observations on patients with primary ventricular fibrillation complicating acute myocardial infarction. Circulation 1975; 52: 755-9.

8 Bennett MA, Wilner JM, Pentecost BL. Controlled trial of lignocaine in prophylaxis of ventricular arrhythmias complicating myocardial infarction. Lancet 1970; ii: 909-11.

9 Pentecost BL. Coronary artery disease. $\mathrm{Br} \mathrm{Med} \mathrm{f}$ 1971 ; i: 93-8.
10 Spracklen FHN, Kimerling JJ, Besterman EMM, Litchfield JW. Use of lignocaine in treatment of cardiac arrhythmias. $\mathrm{Br} \mathrm{Med} \mathcal{f} 1968$; i: 89-91.

11 Chopra MP, Thadani U, Portal RW, Aber CP. Lignocaine therapy for ventricular ectopic activity after acute myocardial infarction: a double-blind trial. $\mathrm{Br}$ Med $\mathcal{F} 1971$; iii: $668-70$.

12 Noneman JW, Rogers JF. Lidocaine prophylaxis in acute myocardial infarction. Medicine (Baltimore) 1978; 57: 501-15.

13 Harrison DC. Should lidocaine be administered routinely to all patients after acute myocardial infarction. Circulation 1978; 58: 581-4.

14 Lie KI, Wellens HJ, van Capelle FJ, Durrer D. Lidocaine in the prevention of primary ventricular fibrillation. $N$ Engl f Med 1974; 291 : 1324-6.

15 Alderman EL, Kerber RE, Harrison DC. Evaluation of lidocaine resistance in man using intermittent large-dose infusion techniques. Am $\mathcal{F}$ Cardiol 1974; 34: 342-9.

16 Darby S, Bennett MA, Cruickshank JC, Pentecost BL. Trial of combined intramuscular and intravenous lignocaine in prophylaxis of ventricular tachyarrhythmias. Lancet 1972; i: 817-9.

17 Prescott LF, Adjepon-Yamoah KK, Talbot RG. Impaired lignocaine metabolism in patients with myocardial infarction and cardiac failure. $\mathrm{Br} \mathrm{Med} \mathcal{F}$ 1976; i: 939-41.

18 Nevins MA. Lidocaine and heart rate (letter). Circulation 1975; 51: 951.

19 Gamble OW, Cohn K. Effect of propranolol, procaineamide and lidocaine on ventricular antomaticity and reentry in experimental myocardial infarction. Circulation 1972: 46: 498-506.

20 Conley MJ, McNeer JF, Lee KL, Wagner GS, Rosati RA. Cardiac arrest complicating acute myocardial infarction: predictability and prognosis. Am f Cardiol 1977; 39: 7-12.

Requests for reprints to Dr B L Pentecost, The General Hospital, Steelhouse Lane, Birmingham B4 6NH. 